\title{
An Analysis on Infected Cases of Corona Virus Using Scientific Computing Methods
}

\author{
Saima Shoro ${ }^{1}$, Noor Ahmed Shaikh ${ }^{2}$, Fahim Shahbaz Shoro ${ }^{3}$, Sadia Anwar ${ }^{4}$ \\ Department Of Computer Science \\ ${ }^{1}$ Shah Abdul Latif University Khairpur Mir;s, Sindh, Pakistan, shorosaima@gmail.com \\ ${ }^{2}$ Shah Abdul Latif University Khairpur Mir;s, Sindh, Pakistan, noor.shaikh@ @alu.edu.pk \\ ${ }^{4}$ Shah Abdul Latif University Khairpur Mir;s, Sindh, Pakistan, Sadiaanwar.26@gmail.com \\ Department of Mechanical Engineering \\ ${ }^{3}$ NED University of Engineering and Technology Karachi, Sindh, Pakistan,fahimshoro17@gmail.com
}

\begin{abstract}
The Corona Virus disease is a worldwide health care issue, and international efforts to manage it have been suggested and discussed. Despite the fact that numerous studies have been done using clinical data and documented infected cases, there is always need for more study since a lot of complex factors are involved in future prediction. As a result, mathematical modeling is an essential tool for estimating critical transmission parameters and forecasting disease model dynamics. We analyze and offer various models for the Corona Virusin this study, which can answer significant concerns regarding global health care and provide crucial suggestions. Euler's method, Runge-Kutta method of order two (RK2) are two well-known numerical approaches for solving such problems. The results, which are based on the numerical approaches provide approximate solutions, provide critical answers to this worldwide challenge. The number of infected, recovered, and quarantined persons in the future can be estimated using numerical findings. The findings might also support worldwide efforts to develop more preventions and enhance intermediation programs. The proposed model can be refereed to be a realistic description of this pandemic.
\end{abstract}

Key words: Corona Virus disease, Mathematical modeling, Euler Method and Runge-Kutta Method.

\section{INTRODUCTION}

The Corona Virus was initially diagnosed as a case of pneumonia with unknown origin, which first emerged in the Chinese city of Wuhan at the end of December 2019 and quickly spread across the country and around the world [1]. The Centre for Disease Control (CDC) of the PRC (People's Republic of China) examined the respiratory samples and determined that the pneumonia was caused by a new corona virus, dubbed Novel Corona VirusPneumonia (NCP) [2]. The corona virus is one of the most common viruses that attack the human respiratory system [3]. The virus was given the name 2019-nCoV by Chinese researchers [4]. The new corona virus was later designated Severe Acute Respiratory Syndrome Coronavirus-2 (SARS-CoV-2) by the International Committee on Virus Taxonomy [5]. The World Health Organization (WHO) named Pneumonia as Corona virus disease-19 (COVID-19) on the same day, February 11, 2020 [6]. On January 30, 2020, the World Health Organization (WHO) classified the Corona Virus outbreak a sixth public health emergency situation (SPHEC) [7]. This was not the first time the Corona Virus has spread. The Severe Acute Respiratory Syndrome Corona virus (SARS$\mathrm{CoV}$ ) and the Middle East Respiratory Syndrome Corona Virus(MERS-CoV) outbreak are two past Corona Virus outbreaks [8]. The Corona Virus is believed to be the third corona virus outbreak, affecting more than 209 nations, including Pakistan. The World Health Organization (WHO) reports a total of 1,093,349 confirmed cases with 58,620 deaths. To far, the United States has had the most positive cases, followed by Italy and Spain [9]. Pakistan's neighboring nations, notably China, were particularly hard hit, with the Corona Virus occurring for the first time. Italy has the largest number of Corona Virus death rate in the west, whereas Iran has the highest number of Corona Virus deaths in the north [10]. On February 26, 2020, the Ministry of Health, 
Government of Pakistan, confirmed the first case of Corona Virus in Karachi, Sindh province. On the same day, the Pakistan Federal Ministry of Health in Islamabad confirmed another case [11,12]. Within fifteen days, there were twenty (20) confirmed cases out of 471 suspected cases, with the Sindh province having the greatest number, followed by Gilgit Baltistan. All of the confirmed patients had been to Iran, Syria, or London recently. And these cases are presently increasing at a rapid rate, putting the situation in jeopardy [13]. With the continual rise in the number of CVOID-19 positive cases, Pakistan's geographical position necessitates a high degree of action, planning, and management. The Ministry of National Health Services, Regulation \& Coordination Pakistan presented a plan titled "National Action Plan for Preparedness and Response to Corona Virus Disease (Covid- 19) Pakistan" on February 12th. The plan aims to control the spread of the virus and strengthen country and community emergency awareness to ensure a timely, efficient, and effective response to potential events. Local, regional, and national waves can have a significant influence on Pakistan's people and society [14]. The Pakistani government has taken a number of measures to combat the Corona Virus outbreak to date.

\section{LITERATURE REVIEW}

There have been a few recent publications on the Corona Virus pandemic. One of the most recent research looked at the prediction and control of Corona Virus, and found that some models based on dynamics were utilized to minimize disease transmission in three Indian states [15]. Also, given the lack of vaccinations or effective treatments around the world, several governments, such as South Korea, Italy, and Brazil, have implemented measures such as social isolation, city lock-downs, and border control to alleviate public fears [16]. Aside from that, important futures for the Corona Virus outbreak in Canada have been assessed using deep learning (DL) models to anticipate the trends and probable stopping time of the unique Corona Virus pandemic throughout the world. Long short-term memory (LSTM) networks have been described before [17]. The mathematical modelling of fourteen nonlinear FDEs was given in another work [18], which dealt with how the transmission dynamics of infection occurred in society. In addition, a shortterm prediction of Corona Virus has been anticipated in Brazil in another study. As long as creating shortterm forecasting models allows for the prediction of future case numbers [19]. To return to the topic of prediction, it has been suggested that the scientific community work together to develop new and better methodologies, strategies, forecasting tools, and models in order to better understand and mitigate the effects of this and future pandemics [20]. An optimum regression tree technique was used in a different study at the time to find the key causative factors that significantly affect case fatality rates for different nations such as Canada, France, India, South Korea, and the United Kingdom [21]. Corona Virus mathematical modelling is working behind the scenes to understand and forecast how diseases spread. Mathematical models are used to construct a simplified representation of infection transmission in a population and to comprehend how a disease could develop in the future. These forecasts might help us make better use of public health resources including vaccinations, treatments, preventions, and interventions. Clinicians and administrators are adopting modelling results without recognizing that the data is simulated. The calculation of sample size requirements is a novel application for mathematical modelling. Estimates of population parameters can be used to guide a simulation that adds one patient at a time until a statistically significant difference between the experimental groups is found. A series of these simulations can provide investigators with a sample size range and midpoint that will satisfy the test of their hypothesis [22]. Because Corona Virus is new and only came out towards the end of 2019, there aren't many imperial research on Corona Virus. Although some research have been proposed in this field, they are insufficient. For instance, in[23], BiaoTang,et al. performed a research. They proposed a deterministic compartmental model based on the disease's clinical progression, individual epidemiological status, and therapeutic methods. Estimates based on probability and model analysis suggest that the control reproduction number might be as high as 6.47, according to their research. Simultaneously, Sha He1, et al. created a model that categorizes the influence of working hours on disease transmission based on the strength of prevention and control measures [24]. Altaf Khan and Atangana, on the other hand, presented a model based on the premise that the seafood industry contains enough sources of disease to infect individuals [25]. More enhancements for the Corona Virus models may be found in [26-27]. Although various mathematical models have been presented for the prediction of novel Corona Virus diseases, some of them can yet be improved. Numerical techniques might be used to generate some approximate solutions for this virus, which could help to enhance forecasts 
and estimates. Runge-Kutta techniques for Corona Virus are an issue that has yet to be investigated. It's critical to find some numerical findings more precisely and broadly in a complex corona virus model. This study makes a contribution by analyzing the Corona Virus model equations and finding the essential model elements using Euler's technique and Runge-Kutta methods.

\section{CURRENT SITUATION IN PAKISTAN}

The current situation of Pakistan is described in the Table: 1 given below:

\begin{tabular}{|l|l|}
\hline Country & Pakistan \\
\hline Total Cases & 966,007 \\
\hline Infected & 1,157 \\
\hline Deaths & 22,469 \\
\hline Vaccinated & $3,363,490$ \\
\hline New Infections & 1,156 \\
\hline
\end{tabular}

Table: 1 Current Situation in Pakistan

\section{METHODOLOGY}

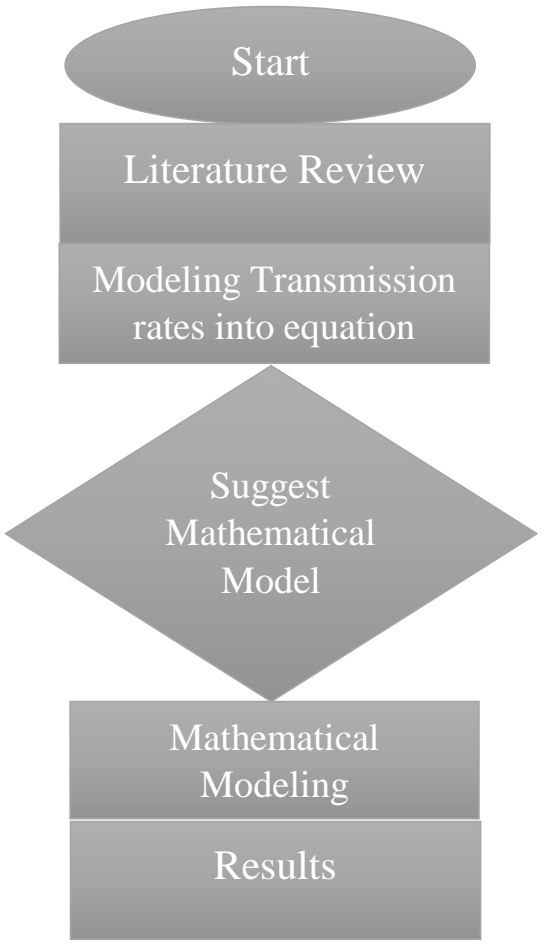

Figure: 1 Methodology

\section{MATHEMATICAL MODELS}

Chemical reactions, ecological interactions, and biological processes are just a few examples of scientific and technological issues that may be theoretically described using systems of ordinary differential equations. There are no accurate analytic solutions to most real-world ordinary differential equations. Numerical methods and computational tools provides support in the development of model solutions [28]. There are a variety of useful numerical approaches for solving initial value problems (IVP) in ordinary differential equations that generate numerical approximations. Historically, Leonhard Euler invented the first numerical technique in 1768, while Carl Runge and Martin Kutta described the RungeKutta method in 1895 and 1905, respectively. Euler's technique and the Runge-Kutta method of order two (RK2) may be used to solve nonlinear infectious disease models with starting populations. [29-30] has further information and examples of numerical techniques with application examples.

\subsection{Euler's Method}

The fundamental explicit technique for solving systems of ordinary differential equations with beginning conditions is Euler's method [31] has further information and examples of this approach. The basic formula for Euler's technique is as follows:

$$
\begin{array}{ll}
\frac{\mathrm{du} 1}{\mathrm{dt}} & =\mathrm{f} 1(\mathrm{t}, \mathrm{u} 1, \mathrm{u} 2 \ldots \mathrm{um}), \\
\frac{\mathrm{du} 2}{\mathrm{dt}} & =\mathrm{f} 2(\mathrm{t}, \mathrm{u} 1, \mathrm{u} 2 \ldots \mathrm{um}), \\
\frac{\mathrm{du} 3}{\mathrm{dt}} & =\mathrm{f} 3(\mathrm{t}, \mathrm{u} 1, \mathrm{u} 2 \ldots \mathrm{um}), \\
\cdot & \\
\cdot & \\
\frac{\mathrm{dum}}{\mathrm{dt}} & =\mathrm{fm}(\mathrm{t}, \mathrm{u} 1, \mathrm{u} 2, \ldots, \mathrm{um}),(5.1)
\end{array}
$$

With the initial conditions

$\mathrm{Ui}$ (a) $=\alpha \mathrm{i}, \quad$ for $\mathrm{i}=1,2, \ldots, \mathrm{m} . \quad(5.2)$ Updatingthefunctionu 1 by $\mathrm{f} 1, \mathrm{u} 2$ by $\mathrm{f} 2, \ldots, \mathrm{um}$ by $\mathrm{fm}$ and using the step size $\mathrm{h}=\mathrm{b}-\mathrm{a} / \mathrm{n}$, formula(5.1) takes the form $u j(i+1)=u j(i)+h f j(t(i), u 1(i), u 2(i), \ldots, u m(i))$, (5.3) where $i=0,1, \ldots, n-1$ and $j=1,2, \ldots, m$. 


\subsection{Runge Kutta Method}

As it is highly precise, stable, and easy to program, the Runge Kutta technique is the most used numerical methodology. This method is the most commonly used since it provides beginning values and is especially useful for constructing higher derivatives [31].

The fundamental RK formulae and the corresponding right-hand-side function, $\mathrm{f} 1$ or $\mathrm{f} 2$ or $\mathrm{f} 3$...or $\mathrm{fm}$, are used to update each unknown functionu1, u2, u3,..., and um, using the Runge-Kutta (RK) technique, which is similar to Euler's approach. The two-stage RK technique (also known as the "midpoint method") is currently considered [32]. If we represent the two update parameters as $\mathrm{k} 1$ and $\mathrm{K} 2$ for the midpoint technique, the fundamental second-order Runge-Kutta formulae are as follows:

k1 =hf(ti,ui),

$\mathrm{k} 2=\mathrm{hf}(\mathrm{ti}+0.5 \mathrm{~h}, \mathrm{ui}+0.5 \mathrm{k} 1)$,

$\mathrm{Ui}+1=\mathrm{ui}+\mathrm{K} 2$.

To apply these formulas to the system (5.2), the parameters $\mathrm{k} 1$ and $\mathrm{K} 2$ for each unknown function should be computed. Consider an integer $\mathrm{n}>0$ and $\mathrm{h}$ $=\mathrm{b}-\mathrm{a} \mathrm{n}$ when $\mathrm{a} \leq \mathrm{t} \leq \mathrm{b}$, and ui(a) $=\alpha \mathrm{i}$ for eachi $=$ $1,2, \ldots, \mathrm{m}$. The values of the parameter $\mathrm{k} 1$ for the unknown functions $\mathrm{u} 1, \mathrm{u} 2 \ldots \mathrm{um}-1$, and um are

$\mathrm{k} 1, \mathrm{j}=\operatorname{hfj}(\mathrm{t}(\mathrm{i}), \mathrm{u} 1(\mathrm{i}), \mathrm{u} 2(\mathrm{i}), \ldots, \mathrm{um}(\mathrm{i}))$, for $\mathrm{j}=1,2, \ldots, \mathrm{m}$. (5.5)

Similarly, the values of $\mathrm{K} 2$ are

$\mathrm{k} 2, \mathrm{j}=\mathrm{hfj}(\mathrm{t}(\mathrm{i})+0.5 \mathrm{~h}, \mathrm{u} 1(\mathrm{i})+0.5 \mathrm{k} 1,1, \mathrm{u} 2(\mathrm{i})$

$+0.5 \mathrm{k} 1,2, \ldots, \mathrm{um}(\mathrm{i})+0.5 \mathrm{k} 1, \mathrm{~m}),(5.6)$

For $\mathrm{j}=1,2, \ldots, \mathrm{m}$. Finally, the values of the unknown functions at the next grid point are given:

$u j(i+1)=u j(i)+k 2, j$, for $i=0,1, \ldots, n-1(5.7)$

It can be noticed that all the values $\mathrm{k} 1,1, \mathrm{k} 1,2, \ldots, \mathrm{k} 1, \mathrm{~m}$ should be computed before identifying the values $\mathrm{k} 2, \mathrm{j}$, for $\mathrm{j}=1,2, \ldots, \mathrm{m}$.

\section{MATHEMATICAL MODEL FOR CORONA VIRUS}

The present corona virus outbreak has turned into a worldwide health-care issue. Some measures for managing the virus have been disclosed, such as limiting contacts as much as possible and advising individuals to stay at home. Mathematical models for this virus are useful in demonstrating model dynamics and forecasting the number of affected people in the future. A mathematical approach for displaying individual interactions and determining the model production number was recently proposed. Clinical progression, epidemiological individuals, and therapeutic strategies are used to create the model. As a result, the model included therapy, isolation (hospitalization), and quarantine as intervention compartments [23]. The model has recently been modified to include a time-dependent dynamic system [33]. In Figure 2, we build the model diagram as well as the interaction individual components and their interaction rates. Eight groups (individuals) are represented in the model: susceptible S, exposed E, symptomatic I, pre-symptomatic A, quarantine susceptible Sq, quarantine exposed Eq, hospitalised $\mathrm{H}$, and recovered $\mathrm{R}$. Table 2 lists all parameter values as well as the initial populations. [23] defined the estimated values, which were subsequently updated in [33]. In our computer simulations, we mostly followed reference [33], and we utilized such values. They employed the Markov Chain Monte Carlo (MCMC) approach to fit the model to the data, and the MCMC procedure was carried out using an adaptive Metropolis-Hastings (M-H) algorithm. [35]

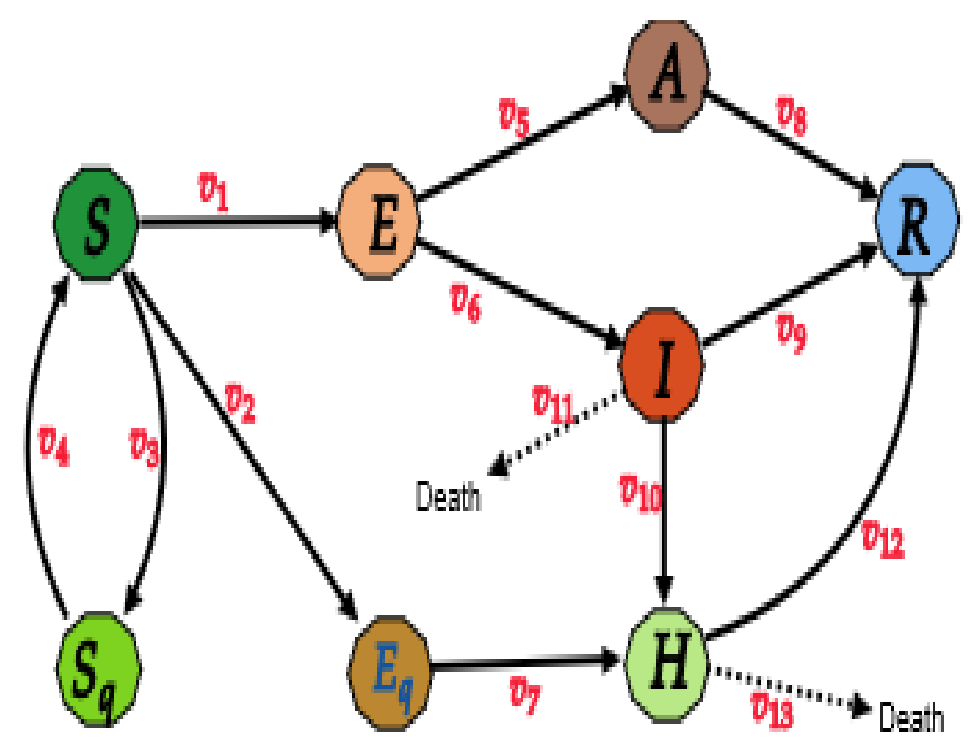

Figure: 2 Mathematical Model 


\begin{tabular}{|c|c|c|}
\hline Parameter & Definition & Value \\
\hline$S(O)$ & Initial susceptible individuals & 11081000 \\
\hline$E(O)$ & Initial exposed individuals & 105.1 \\
\hline$A(O)$ & Initial pre-symptomatic individuals & 53.839 \\
\hline$I(O)$ & Initial symptomatic individuals & 27.679 \\
\hline$S_{q}$ & Initial quarantine susceptible individuals & 739 \\
\hline$E_{q}$ & Initial quarantine exposed individuals & 1.1642 \\
\hline$H(O)$ & Initial hospitalized individuals & 1 \\
\hline$R(O)$ & Initial recovered individuals & 2 \\
\hline$K_{l}$ & Transmission per contact & $2.1011 \times 10-8$ \\
\hline$K_{2}$ & Quarantined exposed rate & $1.2858 \times 10-5$ \\
\hline$K_{3}$ & Transition rate between exposed and infected classes & $\frac{1}{7}$ \\
\hline$K_{4}$ & The multiple of the transmissibility of $A$ to I & 0.3 \\
\hline$K_{5}$ & Quarantined uninfected contact rate & $\frac{1}{14}$ \\
\hline$K_{6}$ & Probability of symptomatic among infected people & 0.86834 \\
\hline$K_{7}$ & $\begin{array}{l}\text { Transition rate between quarantined exposed quarantined infected } \\
\text { classes }\end{array}$ & 0.1259 \\
\hline$K_{8}$ & Recovery rate from symptomatic infected & 0.33029 \\
\hline$K_{9}$ & Recovery rate from asymptomatic infected & 0.13978 \\
\hline$K_{10}$ & Recovery rate from quarantined infected & 0.11624 \\
\hline$K_{11}$ & Infected death rate & $1.7826 \times 10-5$ \\
\hline$a$ & Initial contact rate & 14.781 \\
\hline$b$ & Minimum contact rate & 2.9253 \\
\hline$d$ & $\begin{array}{l}\text { Initial transition rate between symptomatic infected and } \\
\text { quarantined infected class }\end{array}$ & 0.13266 \\
\hline
\end{tabular}

Table:2 Description of Mathematical Model

MATLAB is used to construct numerical approximation solutions of the model for various parameters and initial populations (see Figures 3 and 4). As a result, it may be concluded that the population model states have a different model dynamic. The model variables are numerically simulated on twodimensional planes utilizing parameters and starting populations.
More interestingly, all numerical approximation answers based on the two presented numerical techniques are in good agreement. The findings of this study, which are based on computational simulations, are a significant step forward in forecasting future model dynamics for development programs, treatments, and health-care methods. 
Saima Shoro et al., International Journal of Emerging Trends in Engineering Research, 9(8), August 2021, 1147 - 1155

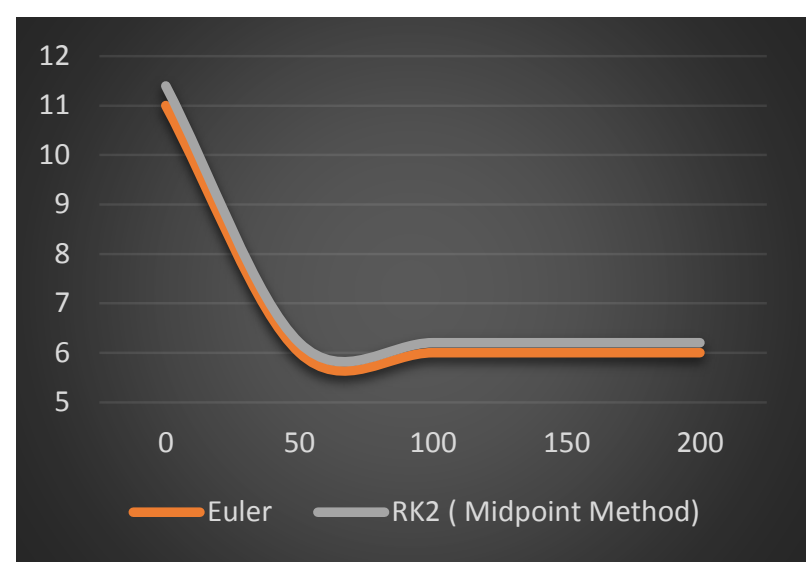

(a)

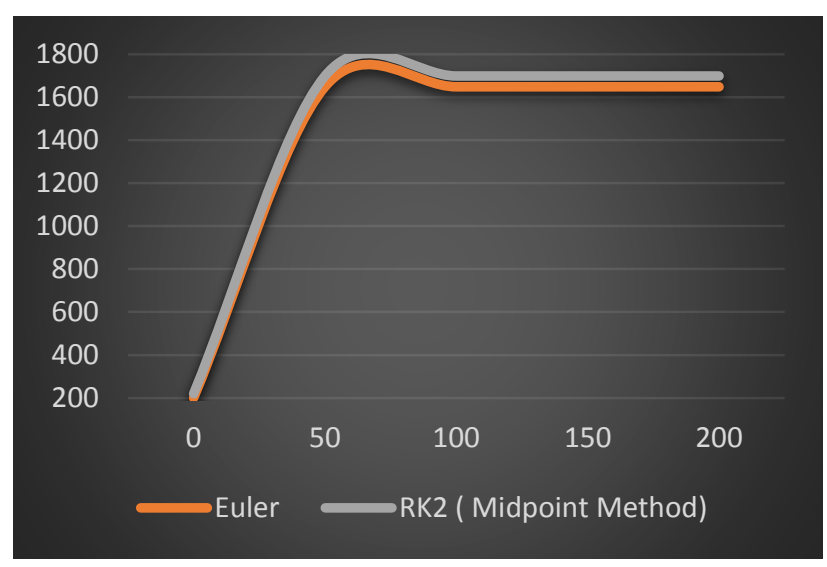

(c)

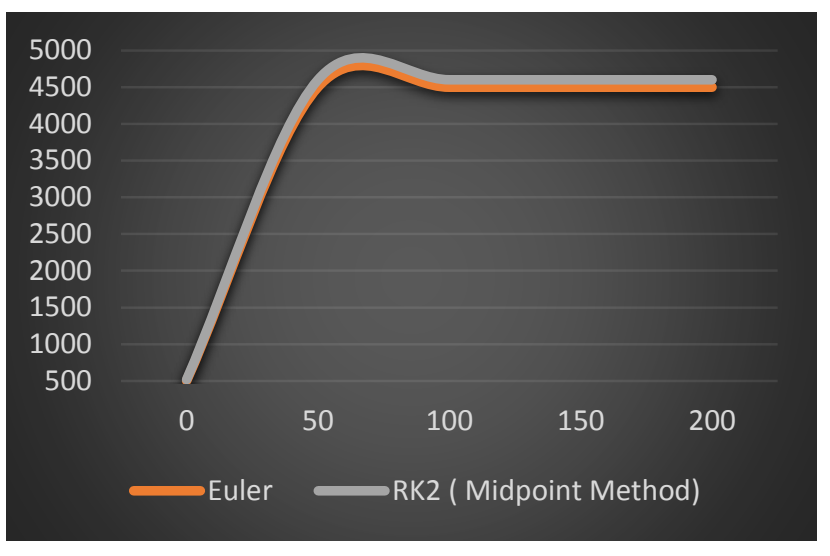

(b)

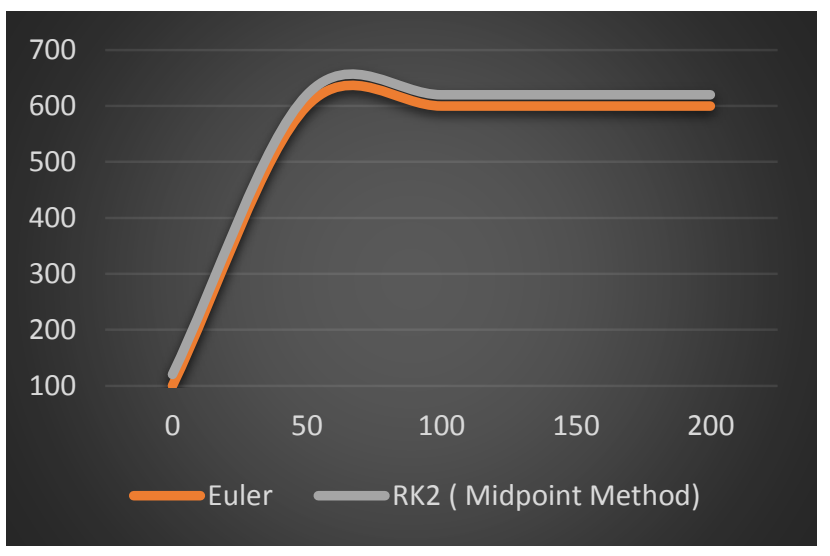

(d)

Figure: 3 Numerical approximate solutions for the corona virus disease model using Euler method and Runge-Kutta method for order two (RK2) (a): the number of susceptible populations S, (b): the number of exposed populations E, (c): the number of symptomatic populations I, (d): the number of pre-symptomatic populations A.

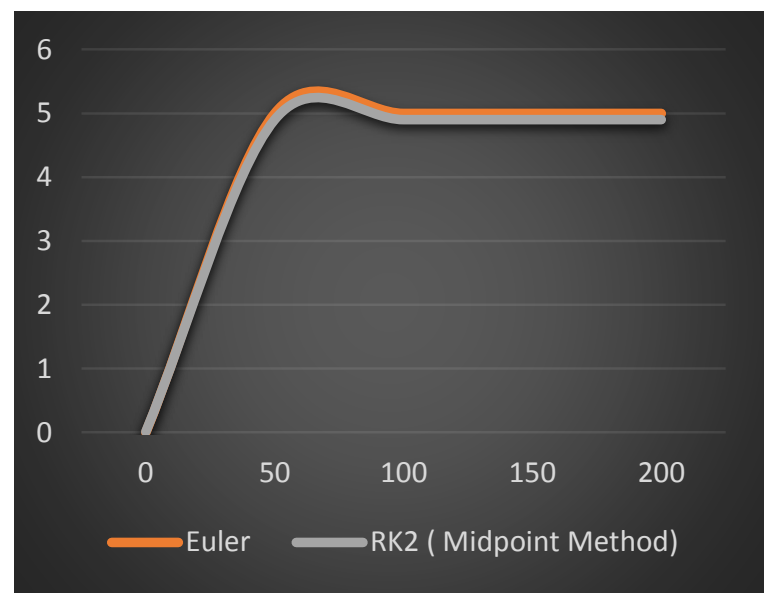

(a)

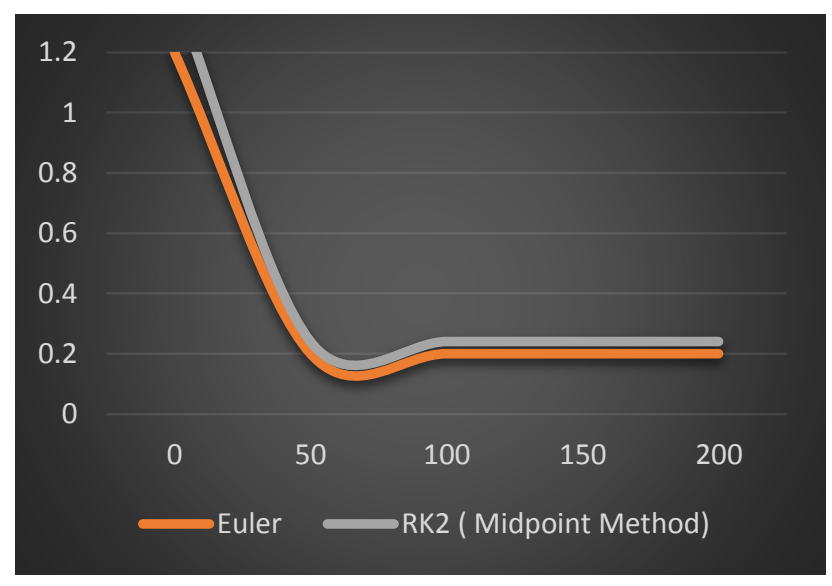

(b) 


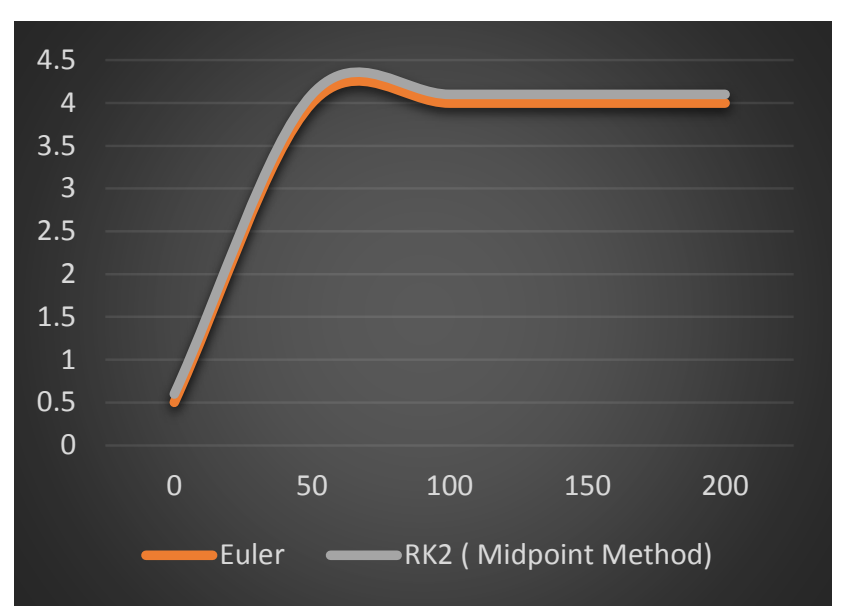

(c)

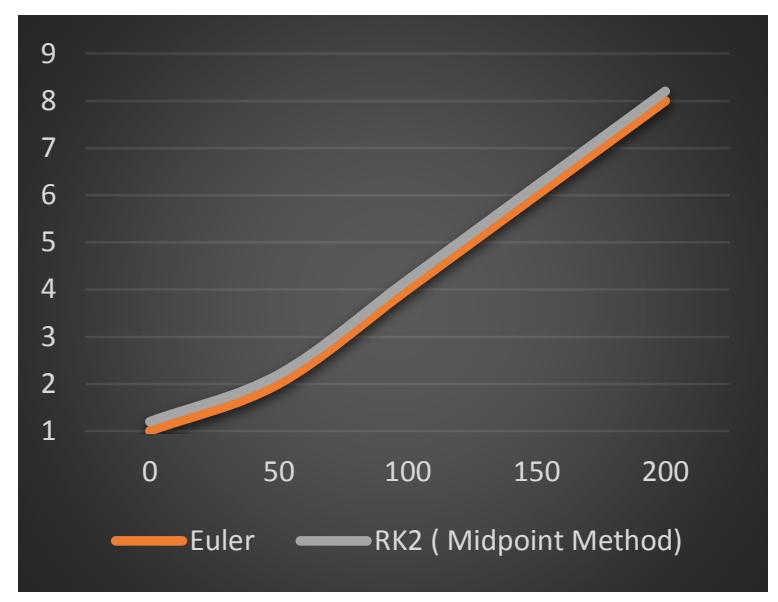

(d)

Figure: 4 Numerical approximate solutions for the corona virus disease model using Euler method and Runge-Kutta method for order two (RK2) (a): the number of quarantine susceptible populations Sq, (b): the number of quarantine exposed populations Eq, (c): the number of hospitalized populations $\mathrm{H}$, (d): the number of recovered populations $\mathrm{R}$.

\section{RESULTS}

The function applies a logistic model for estimation of final pandemic size from daily estimations [34]. The model is data driven, so its forecast is as good as data are. Additionally, it is supposed that the model is a conceivable definition of the one-stage pandemic In this section, we investigate the results of the Pakistan by the proposed model. For Pakistan, we provided data from December 31 to July 31, 2021. The Results are illustrated in Figure: 5

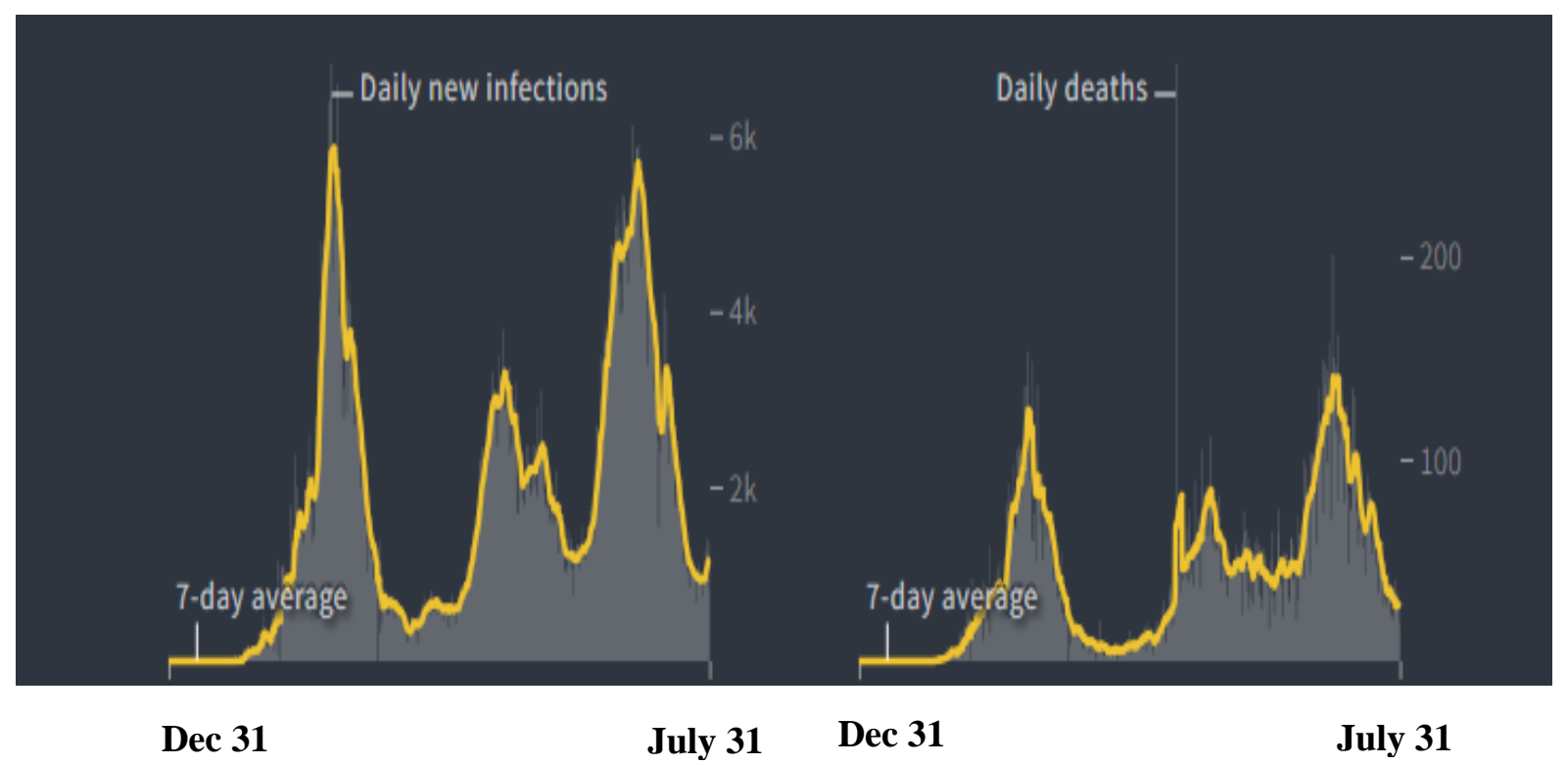

Figure: 5 The Predicted Rates in Pakistan 
Saima Shoro et al., International Journal of Emerging Trends in Engineering Research, 9(8), August 2021, 1147 - 1155

\section{CONCLUSION}

Global efforts are focusing on and discussing a variety of health-care measures for preventing the spread of the novel Corona Virus in the community. As can be seen, this virus has the potential to become a public health problem, spreading quickly among humans. The model of coronavirus disease is complex, and it necessitates the use of mathematical techniques in order to enhance treatments and healthcare programs. The model equations are nonlinear differential equations with numerical solutions that need numerical methods. Based on the stated examples, we used the Euler and Runge-Kutta techniques to derive some approximate solutions for each model state. These are a significant step forward in terms of identifying essential model features and future model enhancement. Computational discoveries might help worldwide efforts to limit the number of people infected with the virus and to prevent it from spreading across the population. As a result, certain findings and computational results are based on the Corona Virus model's proposed techniques. To begin, all sections model dynamics are calculated using two different numerical approaches. The findings of investigating the dynamics of the fall section represent a significant step forward in predicting and analyzing the population of Pakistan. Matlab was used to do the computations and simulations. The findings of this study recommended that health-care programs should focus more on the main model parameters. This might supports community-based initiatives aimed at reducing the effects of coronavirus disease. The number of infected individuals, vulnerable persons, and recovered individuals may all be estimated and predicted using computational findings. The proposed model can be refereed to be a realistic description of this pandemic disease. Surprisingly, the procedures described here may be further improved and used to a wide range of coronavirus models for various instances all over the world. They might beconvenient for future model upgrades, interventions, and vaccination campaigns.

\section{REFERENCES}

1. Sahin AR, Erdogan A, Agaoglu PM, Dineri Y, Cakirci AY, Senel ME, Tasdogan AM. 2019 novel coronavirus (COVID-19) outbreak: a re- view of the current literature. EJMO 2020;4(1):1-7.
2. Wang LS, Wang YR, Ye DW, Liu QQ. A review of the 2019 Novel Coronavirus (COVID-19) based on current evidence. Int $\mathrm{J}$ Antimicrob Agents 2020:105948.

3. Hoehl S, Rabenau H, Berger A, Kortenbusch M, Cinatl J, Bojkova D, Neumann P. Evidence of SARSCoV-2 infection in returning travelers from wuhan, China. New England J Med 2020;382(13):1278-80.

4. Zhu N, Zhang D, Wang W, Li X, Yang B, Song J, Niu P. A novel coronavirus from patients with pneumonia in China, 2019. New En- gland J Med 2020;382(8):727.

5. Zu ZY, Jiang MD, Xu PP, Chen W, Ni QQ, Lu GM, Zhang LJ. Coro- navirus disease 2019 (COVID-19): a perspective from China. Radi- ology 2020. 200490200490.

6. Rodriguez-Morales A, Tiwari R, Sah R, Dhama K. COVID-19, an emerging coronavirus infection: current scenario and recent developments-an overview. J Pure Appl Microbiol 2020;14:6150.

7. Bilgin S, Kurtkulagi O, Kahveci GB, Duman TT, Tel BMA. Millennium pandemic: a review of coronavirus disease (COVID-19). Exp Biomed Res 2020;3(2):117-25.

8. Zhou P, Yang XL, Wang XG, Hu B, Zhang L, Zhang $\mathrm{W}$, Chen HD. A pneumonia outbreak associated with a new coronavirus of probable bat origin. Nature 2020;579(7798):270-3.

9. World health organization (WHO). https://www.who.int/emergencies/ diseases/novelcoronavirus-2019.

10. Saqlain M, Munir MM, Ahmed A, Tahir AH, Kamran S. Is Pakistan pre- pared to tackle the coronavirus epidemic? Drugs Ther Persp 2020:1-2.

11. Ali I. Pakistan confirms first two cases of coronavirus, govt says "no need to panic". https://www.dawn.com/news/amp/1536792.

12. Geo news. https://www.geo.tv/latest/274482-pakistanconfirms-first. [Accessed 4 April 2020].

13.COVID-19 live dashboard (Pakistan): national institute of health Islamabad. https://www.nih.org.pk/novel-coranavirus-2019ncov/. Accessed 5th April 2020.

14. National action plan for preparedness \& response to Corona virus disease (Covid-19) pakistan. https//www.nih.org.pk/wp-content/ uploads/2020/02/NAP-covid-19_AL@ @ersion-3-date- 
12-2-2020-with- annexures.pdf. Accessed 5th April 2020.

15. Mandal M, Jana S, Nandi SK, et al. (2020) A model based study on the dynamics of COVID-19: prediction and control. Chaos Soliton Fract 136: 109889.

16. Reis RF, de Melo Quintela B, de Oliveira Campos J, et al. (2020) Characterization of the COVID- 19 pandemic and the impact of uncertainties, mitigation strategies, and underreporting of cases in South Korea, Italy, and Brazil. Chaos Soliton Fract 136: 109888.

17. Chimmula VKR, Zhang L (2020) Time series forecasting of COVID-19 transmission in canada using LSTM networks. Chaos Soliton Fract 135: 109864.

18. Abdo MS, Shah K, Wahash HA, et al. (2020) On a comprehensive model of the novel coronavirus (COVID-19) under Mittag-Leffler derivative. Chaos Soliton Fract 135: 109867.

19. Ribeiro MHDM, da Silva RG, Mariani VC, et al. (2020) Short-term forecasting COVID-19 cumulative confirmed cases: perspectives for Brazil. Chaos Soliton Fract 135: 109853.

20. Boccaletti S, Ditto W, Mindlin G, et al. (2020) Modeling and forecasting of epidemic spreading: The case of Covid-19 and beyond. Chaos Soliton Fract 135: 109794.

21. Chakraborty T, Ghosh I (2020) Real-time forecasts and risk assessment of novel coronavirus (COVID19) cases: a data-driven analysis. Chaos Soliton Fract 135: 109850.

22. Riou J, Althaus CL (2020) Pattern of early humanto-human transmission of Wuhan 2019 novel coronavirus (2019-nCoV), December 2019 to January 2020. Eurosurveillance 25: 2000058.

23. Tang B, Wang X, Li Q, et al. (2020) Estimation of the transmission risk of the 2019-nCoV and its implication for public health interventions. J Clin Med 9: 462. AIMS Bioengineering Volume 7, Issue 3, 130-146.145

24. He S, Tang S, Rong L(2020)AdiscretestochasticmodeloftheCOVID19outbreak: forecastand control. Math Biosci Eng 17: 2792 - 2804 .

25. Khan MA, Atangana A (2020) Modeling the dynamics of novel coronavirus (2019-nCov) with fractional derivative. DOI: https://doi.org/10.1016/j.aej.2020.02.033.
26. Kucharsk A J, Russell TW, Diamond C, etal.(2020)Early dynamics of transmission and control of COVID-19: a mathematical modelling study. Lancet Infect Dis 20: 553-558.

27. Li LQ, Huang T, Wang YQ, et al. (2020) COVID19 patients' clinical characteristics, discharge rate, and fatality rate of meta-analysis. J Med Virol 92: 577-583.

28. Shawagfeh N, Kaya D (2004) Comparing numerical methods for the solutions of systems of ordinary differential equations. Appl Math Lett 17: 323 - 328.

29. Burden RL, Faires JD (2011) Numerical Analysis, 9 Eds., USA: Brooks/Cole, Cencag Learning.

30. King MR, Mody NA (2010) Numerical and Statistical Methods for Bioengineering: Applications in MATLAB, UK: Cambridge University Press.

31. Islam MA (2015) A comparative study on numerical solutions of initial value problems (IVP) for ordinary differential equations (ODE) with Euler and Runge Kutta Methods. Am J Comput Math 5: 393-404.

32. Fausett LV (1999) Applied Numerical Analysis Using MATLAB, New Jersey: Prentice hall.

33. Tang B, Bragazzi NL, Li Q, et al. (2020) An updated estimation of the risk of transmission of the novel coronavirus (2019-nCov). Infect Dis Model 5: 248-255.

34. Batista M, fitVirus, MATLAB Central File Exchange, 2020. Available from: https://www.mathworks.com/matlabcentral/ fileexchange/74411-fitvirus. 